\title{
A NOVA ERA COM UM JEITINHO BRASILEIRO: \\ O CASO DO VALE DO AMANHECER
}

\author{
Amurabi Oliveira ${ }^{1}$
}

Resumo: A Nova Era tem sido um fenômeno de difícil apreensão, devido mesmo a heterogeneidade de práticas e valores que ela abarca (Hervieu-Léger, 2008; Amaral, 2000; Magnani, 1999), incluindo aí aquelas que não são necessariamente religiosas. Amaral (1999; 2000) argumenta que a Nova Era caracteriza-se pela retirada dos mais diversos elementos de seus contextos originais, arranjando-os e rearranjando-os de forma performática. Em sua origem, encontramos a convergência de diversos discursos e práticas, em especial, uma busca pela convergência entre oriente e ocidente. Ao ganhar visibilidade no Brasil, a Nova Era ganha também contornos próprios, não apenas reproduzindo o que é produzido no contexto europeu e americano, como também articulando com elementos presentes nas religiosidades populares, em especial com o catolicismo, o espiritismo kardecista e a as religióes afro-brasileiras, debate este que ainda produz opiniōes divergentes em meio a especialistas. Buscamos aqui destacar a singularidade que toma a Nova Era no Brasil, tomando o Vale do Amanhecer como um caso emblemático, em que esta articulação do discurso originário da Nova Era com a religiosidade popular brasileira se dá de forma mais clara.

Palavras-chave: Antropologia da Religião; Nova Era; Vale do Amanhecer; Sincretismo Religioso.

Abstract: The New Age has been a difficult phenomenon to grasp, because even the heterogeneity of the pratices and values that it embraces (Hervieu-Léger, 2008; Amaral, 2000; Magnani, 1999) procedures, including those that are not necessarily religious. Amaral $(1999 ; 2000)$ argues that the New Age is characterized by the removal of the most diverse elements of their original contexts, arranging them and rearranging them in a performative way. In its origin, we find the convergence

\footnotetext{
${ }^{1}$ Doutor em Sociologia, professor da Universidade Federal de Alagoas, atuando no Programa de Pós-Graduação em Sociologia.
} 
of different discourses and pratices, in particular, a search for convergence between east and west. By gaining visibility in Brazil, the New Age also gets its own configurations, not just reproducing what is produced in the European and American contexts, as well as linking to elements presents in the african-Brazilian religious, debate that still produces differents opnions amoong experts. We seek here to highlight the uniqueness that makes the New Age in Brazil, taking the Valley of Dawn as a typical case in which this articulation of original speech of the New Age with popular Brazilian Religions is given more clearly.

Keywords: Anthropology of Religion; New Age; Valley of Dawn; Religious Syncretism.

\section{RELIGIÃO, DEVANEIO E SINCRETISMO: UM OLHAR SOBRE O BRASIL}

Discorrer acerca de religiosidade, num país marcado por um processo de construção imaginária tão pulsante como o Brasil, é um desafio e tanto. Holanda (2006) já apontara as visões cruzadas que construíram sobre estes lados do Atlântico, ressaltando o aspecto edênico construído pelos europeus em torno da Terra Brasilis. Mas não só de menções ao paraíso se construía o imaginário em torno do Brasil, o inferno estava à espreita, o calor voluptuoso, sua população desnuda e canibalesca trazia consigo a marca de um lugar selvagem, bacante, afrodisíaco, e, por consequência, demoníaco. Seus habitantes, além de corpos tomados por padrões não europeus, também possuíam cosmovisões não eurocêntricas, o imaginário do paraíso perdido em meio às águas (Eliade, 2000) complexificava-se cada vez mais.

Um Estado mais lânguido nos anos iniciais da colonização também contribuiu para a lenta "europeização" dos trópicos, e sendo este Estado Luso, que segundo Freyre (2005) seria formado por um povo de caráter mais "plástico", mais passível a agregar valores. Mas gradativamente a Europa avançou sobre os corpos e almas que habitavam os trópicos, numa divisão tácita do trabalho entre Estado e Igreja, respectivamente, ainda que tenha havido momentos de tensão entre os mesmos (RIBEIRO, 2006). 
A presença de um Estado Católico leva o campo religioso brasileiro a se configurar como um campo em continuo diálogo com o catolicismo, este passa à instância de legitimação das práticas religiosas, Catholicussum: catholicae nil a me alienum puto, poderíamos dizer que esta passa a ser a máxima do campo religioso brasileiro. No entanto, o catolicismo por aqui instaurado toma ares tropicais, incorporando elementos de sua realidade nas Américas, Bastide (1985) já apontara acerca das diferenças apresentadas entre o catolicismo Ibérico e o Brasileiro.

Não só o catolicismo incorpora elementos, como também seus elementos transbordam para as demais práticas religiosas, sendo emblemático o caso das religióes afro-brasileiras, em que os orixás são mascados pelos santos católicos, num complexo jogo de analogias (Bastide, 1985). Podemos destacar que, para além das metáforas criadas pelo/no sincretismo ${ }^{2}$, as relações de poder estabelecidas na sociedade colonial são o sustentáculo principal para se pensar o sincretismo, neste exemplo histórico, considerando a própria negação do sujeito negro que assimila elementos do grupo dominado para legitimar sua posição no mundo (Fanon, 2008). Claro que, o sincretismo não é um fenômeno unívoco ou estanque, muito pelo contrário, até mesmo porque, se o compreendemos como uma transformação da própria identidade do "eu" através do contato com o outro (Sanchis, 1999), significa dizer que o sincretismo impacta os sujeitos e grupos envolvidos, e não apenas o "dominado", dentro das relações de poder estabelecidas. A este respeito Sanchis (2001) nos chama a atenção para o fato que:

Arrancado do húmus particular que assegurava seu crescimento antropológico, o catolicismo português viu-se jogado num espaço aberto e sem fim, onde encontrou sincronicamente universos simbólicos diferentes, através da forçada

\footnotetext{
${ }^{2}$ Devemos destacar que o sincretismo pode ser entendido a partir de "[...] um processo fundamental, tendencialmente universal ainda que diferenciado em seus graus, níveis e modalidades: O processo de usar relações apreendidas no mundo do outro para entender, modificar e/ou eventualmente transfigurar seu próprio universo simbólico, ou ainda o modo pelo qual as sociedades humanas, quando confrontadas - igual ou desigualmente - a outra sociedade, outro grupo social, ou simplesmente outra visão do mundo, redefinem sua própria identidade a partir da alteridade cultural (Sanchis, 1994, p. 10).
} 
aproximação das identidades de três povos desenraizados. Encontro sem dúvida, estruturalmente desigual. E não se pode esquecer um macroprocesso de persistente dominaçãa, exploração, etnocídio intencional, quase genocídio. Apesar dele, no entanto, em seu avesso ou em seus interstícios, deram-se, em níveis individual ou de grupo, coletivo também, mas quase nunca entre as instituiçôes, os microprocessos de um jogo mais variegado das identidades - hostilmente confrontadas como dominantes e dominadas, mas também correlatas, cruzadas, justapostas, articuladas, sem nunca serem definitivamente confundidas. (Sanchis, 2001, p. 25).

Souza (1986), com base em Bastide (1985), chama a atenção para o fato que, com a mudança para as Américas, muitos orixás deixaram de ser cultuados, tendo em vista o novo contexto social no qual os africanos escravizados se inseriam sendo assim, deixava de fazer sentido cultuar deuses relativos às colheitas, se estas só implicariam em mais trabalho, e em benefícios para aqueles que os oprimiam, ou mesmo os deuses da fertilidade, considerando que só trariam mais crianças a serem escravizadas. Em contrapartida, deuses da vingança, como Exu, da guerra, como Ogum, ou da justiça, como Xangô, passaram a ser cultuados mais fortemente, este último inclusive passa a ser tomado como sinônimo do próprio culto, ou do local de culto, como em Alagoas e em Pernambuco (Bastide, 2001).

O elemento indígena também esteve presente, seja através dos movimentos de caráter messiânico chamados de santidades, que existiram com certa força no início do Brasil Colônia (Souza, 1986; Andrade, 2002), seja através de outras reminiscências que se articularam aos elementos católicos e africanos, seja através de seus cultos e cosmovisões mantidos mesmo com o processo de colonizaçãa ${ }^{3}$.

Elementos outros também estiveram presentes desde os momentos iniciais, Freyre (2005) chama a atenção da existência dos elementos orientais

${ }^{3}$ Já no século XX podemos perceber o reavivamento de alguns elementos presentes nos sistemas de crença indígenas, ainda que alguns se apresentem mais no nível da performance, como é o caso dos caboclos na umbanda, bem como a utilização ritualística da Ahyuasca por religiões como o Santo Daime, União do Vegetal e Barquinha. 
presentes através dos judeus (convertidos ou não), ou mesmo da herança moura que o mundo Ibérico traria para o Novo Mundo.

Diante deste cenário fica-nos claro quão diverso se configura o campo religioso brasileiro, desde a sua gênese, o que não chega a ser uma afirmação original. Mais interessa-nos chamar a atenção para como as identidades se articulavam nesse período histórico, bem como o caráter singular que a vivência religiosa vai tomando neste momento.

Ainda que pensemos em identidades fixas neste cenário, seria precipitado realizar uma afirmação de caráter tão categórico, pois, por mais que não houvesse a flexibilização identitária que percebemos na atual conjuntura, não podemos negar que mesmo neste período histórico não devemos apenas simplificar a questão, categorizando um leque amplo de identidades sob o rótulo de estanques. Devemos considerar que sempre houve conversões religiosas, forçadas ou não, mas que em todo caso nos levam a pensar sobre o processo de negociação da realidade social, na medida em que se cria uma identidade religiosa pública e outra privada, articuladas e porosas entre si.

Da mesma forma, o próprio sincretismo deve ser pensado como uma instância em que as identidades religiosas se dinamizam, se constituem e se transformam, não olvidando a dimensão das relaçóes de poder postas, mas que devemos perceber que as escolhas realizadas se baseiam nestas relações, mas também apresentam uma dimensão subjetiva e intersubjetiva. Tomando o caso dos sincretismos afro-católicos, podemos destacar o fato de que os mesmos santos são, por vezes, sincretizados com diferentes orixás, bem como ocorre também o inverso, o mesmo orixá é sincretizado em muitos casos com santos distintos.

A fluidez da identidade religiosa se apresenta de forma mais ou menos explícita, considerando os diversos contextos em que a mesma se insere, no entanto, ela sempre se encontra presente. A distância geográfica da Colônia em relação à Europa pesou para que as identidades aqui fossem mais frouxas, permitindo que a Ilusão de Catequese (Nina Rodrigues, 2006) acontecesse.

Tal frouxidão habitou os corpos e os imaginários religiosos, as procissões festivas e dançantes do catolicismo agregavam elementos deveras plurais, nas festividades o profano não só tocava o sagrado como se imbricava lascivamente a ele. 
Mesmo o demônio, que com a inquisição habitava todos os lugares, abrasileirou-se. Mais que o Exu ter-se tornado diabo, o diabo torna-se Exu. Assim como o Deus Cristão, da Igreja Apostólica Romana, o diabo também era demasiadamente distante, intransigente, impessoal no sincretismo afro-brasileiro o diabo passa a abrir-se a novas possibilidades, seus feitos e feitios podem ser negociados, comprados, o Jeitinho brasileiro, nos termos de DaMatta (1997), se faz presente também no modo do brasileiro de lidar com o sagrado, com aquela instância, que em princípio, seria transcendente e acima das vontades e desejos humanos.

\section{ESOTERISMO, NEOESOTERISMO E NOVA ERA: POLIFONIA E POLISSEMIA}

Podemos tomar, ante aos argumentos desenvolvidos até aqui, como pressuposto o caráter singular e plural da religiosidade no Brasil. Tal característica torna-se ainda mais evidente com o advento da modernidade, e as possibilidades postas pela sociedade Pós-Tradicional (Giddens, 1991). Neste novo cenário as identidades religiosas assumem um caráter cada vez mais subjetivo, e intersubjetivo, trazendo para a esfera individual as possibilidades de arranjos identitários.

Tais arranjos se sobrepõem a uma infinidade de elaborações desenvolvidas pelos indivíduos, que neste sentido, constroem sua realidade sob a égide de uma constante inventividade de sua realidade, e de seu cotidiano. Segundo Velho (2003) nas sociedades ditas complexas: "Os indivíduos vivem múltiplos papeis, em função dos diferentes planos em que se movem, que poderiam parecer incompatíveis sob o ponto de vista de uma ótica linear." (Velho, 2003, p. 26).

Claro que, o grau de manobra do indivíduo, no plano da elaboração de sua identidade religiosa, vai depender de uma série de fatores que o situa socialmente. Questões como classe, gênero, grupo etário, cor, vão pesar significativamente sobre as possibilidades de ampliação ou restrição de seu universo de escolhas e de elaboração. 
Podemos arriscar afirmar que, a Nova Era surge em consonância à este ethos individualista moderno, que não exclui, em absoluto, a experiência comunitária, apenas realiza um giro em termos de possibilidades postas à esfera da subjetividade, bem como às contradições geradas pelas identidades religiosas herdadas e aquelas vivenciadas, experienciadas e escolhidas nos diversos percursos biográficos dos sujeitos.

Para Amaral (1999; 2000; 2003,) a Nova Era caracteriza-se pela possibilidade posta de arranjar, desarranjar ou rearranjar elementos de tradições já existentes, e distintas, e se utilizar de tais elementos enquanto metáforas para expressar performaticamente uma dada visão, em determinado momento, com determinados objetivos postos.

Podemos afirmar que sua origem histórica remonta a um entrecruzamento do discurso oriental com o ocidental, articulando práticas presentes no ocultismo esotérico europeu. Este processo inicia-se no final do século XIX, mas passa a ganhar corpo já no século XX, em especial na sua segunda metade, com a emergência da contracultura, com o cenário político e econômico que passa a dar relevo a aspectos ligados a uma cultura não ocidental. Amaral (1999) ao pensar a Nova Era pontua que nas origens deste fenômeno podemos destacar o Transcendentalismo, o Espiritualismo, a Teosofia, a New Thought e a Christian Science.

Devido a esta ligação com o esoterismo europeu, Magnani (1999) chama a atenção para a necessidade de distinção, no plano linguístico, da vivência do esoterismo europeu destas novas práticas, utilizando-se do prefixo neo para tal finalidade. $\mathrm{O}$ autor dá a seguinte justificativa para a utilização do termo:

[...] o prefixo neo cumpre a função de estabelecer a necessária diferença em relação a dois usos já consagrados da categoria esotérico: em termos técnicos, no campo de estudo das religiões e sistemas iniciáticos. Esotérico designa aqueles ritos ou elementos doutrinários reservados a membros admitidos a um circulo mais restrito, opondo-se, assim, a exotérico, a parte pública do cerimonial.(Magnani, 1999a, p. 13) 
Ou seja, trata-se aqui de um novo momento, em que as possibilidades postas pelo esoterismo são reformuladas, rearranjadas com uma série de outras possibilidade, incluindo aí o orientalismo. Não à toa nos anos $60 \mathrm{e}$ 70 , em especial, houve um intenso fluxo entre oriente e ocidente, incluindo a vinda de gurus ao ocidente, e a ida de ocidentais ao oriente em busca da sabedoria presente nesta região do globo. Neste sentido, podemos afirmar que o neo-esoterismo é uma síntese tanto no nível das práticas quanto dos discursos.

É claro que tal elaboração também será permeada pelas relações de poder estabelecidas entre o ocidente e o oriente, em especial, se compreendermos este último como uma invenção do primeiro, no sentido de uma elaboração discursiva que pode ser apropriada a partir de relações de poder e de dominação, como nos aponta Said (2007).

Outros autores, como Mello (2004), ao tratarem deste novo momento na religiosidade contemporânea, falam em novas gnoses, que possuem as seguintes implicações para a autora:

[...] reabilitamos as chamadas ciências ocultas, antigas tradições orientais, a astrologia, a alquimia, a vidência, as magias, as simpatias, a prática mediúnica e uma infinidade de terapias alternativas que se encontram no arrière-plan de grupos esotéricos e seitas doutrinárias que pretendem deter os segredos das verdadeiras ciências fundadas sobre o mistério, o secreto e as grandes verdades esquecidas (Mello, 2004, p. 103).

Sendo assim, o neo esoterismo é uma readaptação do esoterismo moderno, sendo muito mais aberto e menos rigoroso em sua ritualização e prática. Com efeito, suas práticas são passíveis de constantes ressignificações e reconstruçóes como aponta Guerriero (2006). Neste novo momento, inúmeros elementos são articulados, incluindo aí aqueles presentes no cinema, na música, na literatura etc. Notoriamente o processo de transnacionalização dos bens simbólicos e culturais, apontado por Ortiz (2006), também comporá tal realidade.

Carvalho (1994) nos chama a atenção para o caráter singular do esoterismo moderno, segundo o autor: 
Considero o esoterismo moderno como sendo um grande movimento, intelectual e espiritual, constitutivo da religiosidade contemporânea, e que mantém com o cristianismo uma posição conflitiva. Por um lado, o esoterismo expandiu-se criticando o catolicismo por ter perdido seu lado iniciático, o caminho do auto-conhecimento, além do seu caráter oficial e político de articulador da vida comunitária e legitimador do controle do Estado sobre o indivíduo [...] teria fechado o caminho da religiosidade plena para maioria de seus fiéis (1994, p. 7).

A pluralidade existente nesta nova forma de esoterismo parece apontar para outras direções, além das levantadas pelo autor. A relação com o cristianismo, por exemplo, não se marca apenas pelo conflito, pois o diálogo com o cristianismo de modo geral, e com o catolicismo de modo particular, mostra-se fundamental para o processo de legitimidade destas novas expressões religiosas, ao menos para um número significativo delas - como é o caso do Vale do Amanhecer, das Religiōes ayahuasqueiras, da Umbanda Esotérica etc. - bem como, o caráter iniciático é mantido por várias denominações, ainda que mantenham uma dimensão pública, não inciática, normalmente centrada na oferta de serviços espirituais.

Devemos destacar também que, as práticas da Nova Era ingressam no Brasil através das classes médias/médias altas (Amaral, 1999; Magnani, 1999; 2000), refletindo os interesses das mesmas. Neste momento inicial a síntese entre o esoterismo ocidental com o discurso oriental olvidou diversas práticas presentes nas expressóes da religiosidade popular no Brasil, como as presentes no espiritismo, no catolicismo e, mais ainda, entre aqueles presentes nas religiōes afro-brasileiras. As técnicas corporais dos xamãs siberianos, os escritos de Castañeda, a medicina ayurvédica tomavam um lugar mais central nesta síntese que a pajelança indígena brasileira, ou os serviços espirituais prestados pelos encantados das religióes afro-brasileiras. Tudo aquilo que era considerado simbolicamente deslegítimo, para as classes médias/médias altas brasileiras, naquele momento, era afastado deste universo da Novas Era, ao menos enquanto elementos que tivessem maior visibilidade.

O que nos importa destacar aqui é que tal síntese, considerando os elementos oriundos da religiosidade popular brasileira, não ganhou visibilidade 
no primeiro momento do boom da Nova Era no Brasil ${ }^{4}$, porém, este mesmo movimento viabilizou que religiosidades como o Santo Daime, Vale do Amanhecer, Umbanda Mística etc. tornarem-se mais conhecidas no plano nacional, não à toa tais movimentos abrem suas primeiras filiais nos anos 80 .

Embora estudiosos da Nova Era, entre eles, Amaral (1999; 2000) e Bittencourt Filho (2003) ressaltem como característica principal do movimento a multiplicidade das experiências e a falta de profundidade entendemos que, não se pode tomar apenas um aspecto como característica essencial de um fenômeno tão complexo coma Nova Era, tendo em vista que este apresenta características múltiplas e contrastantes. Numa crítica às iniciativas anteriores, outros autores, entre os quais, Siqueira (2003), Silva (2000), Carvalho (1999), Guerreiro (2006), Magnani (1999) e Oliveira (2008; 2009) preferem destacar a diversidade do mesmo. Pois acreditam que não se pode facilmente aprisioná-lo em categorias limitadas uma vez que em seu diversificado universo observam-se tendências múltiplas e contrastantes. E, do mesmo modo que ele abriga "comunidades sem essência" (Amaral,1999), também comporta rígidas comunidades congregacionais, como tais, a Hare Khrishna, a Sokagakai, o Santo Daime e o Vale do Amanhecer, entre outros.

\section{O JEITINHO DA NOVA ERA: SINCRETISMO, MOVIMENTO E MALEMOLÊNCIA NO BRASIL}

Como bem nos alardeia Ferretti (1995), o sincretismo é um termo essencialmente polissêmico, apropriado por diversas formas entre os autores do pensamento social, o autor nos chama a atenção de como o termo foi utilizado por pesquisadores como Nina Rodrigues, ${ }^{5}$ Arthur Ramos, Gonçalves Fernandes, Waldemar Valente, Herskovits, Roger Bastide, dentre

${ }^{4}$ Ainda que não neguemos que os mesmos se encontravam presentes, ainda que em menor grau, com um especial destaque para as referências ao espiritismo kerdecista, e às referências aos povos indígenas.

${ }^{5}$ No caso específico de Nina Rodrigues, devemos destacar que o autor não se utiliza no decorrer de sua obra do termo sincretismo, ainda que ele discorra sobre o fenômeno utilizando-se de expressões equivalentes, como fusão e dualidade de crenças, justaposição 
outros, também o termo é interpretado por diversas formas pelos atuais pesquisadores. Segundo Munanga (1989), os pesquisadores das religiōes afro-brasileiras dividem-se em dois grupos: os que defendem que realmente houve um sincretismo entre as religiōes africanas e o catolicismo, e aqueles que negam que o mesmo tenha ocorrido. Para o autor, ambos se equivocam ao partir do conceito para a realidade, não analisando de forma adequada nem o conceito, nem a realidade.

Alguns autores têm se utilizado da categoria hibridismo, em muito influenciado por pesquisadores como Hall (2009) e Canclini (1997), como um substituto para o termo sincretismo. Todavia, optamos por continuar nos utilizando deste, por entendermos que o hibridismo remete a fenômenos culturais de modo geral, que tomam maiores proporçôes na sociedade moderna, abarcando também o que ocorrer no plano religioso, no entanto, a categoria sincretismo traz, dentro da acepção que vem sendo trabalhada predominantemente nas ciências sociais, a perspicácia, e a especificidade de se apreender a dinâmica do fenômeno religioso.

Evidentemente que, o universo da Nova Era abarca uma infinidade de práticas, envolvendo, inclusive, algumas não religiosas (Amaral, 1999; 2000; Magnani, 1999; Guerriero, 2006), de modo que, o termo hibridismo poderia parecer mais condizente com esta realidade. Contudo, ao nos focarmos especificamente em uma prática religiosa, vivenciada neste universo, acreditamos que, a categoria sincretismo ganha destaque.

O sincretismo, enquanto fenômeno social, está presente nas mais diversas práticas religiosas, do catolicismo rural ao neopentecostalismo, do kardecismo ao Santo Daime. Sendo assim, a sua presença não seria olvidada no universo da Nova Era mais que isso, ele se apresenta como o sustentáculo principal desta complexa realidade, alguns autores o chamarão de "Sincretismo deslizante" (Oliveira, 2010), ou mesmo de "Sincretismo em Movimento" (Amaral, 1999).

Se tomarmos como parâmetro a definição posta por Amaral (1999), de fato, não há como pensar Nova Era sem pensar o sincretismo, pois "A

de exterioridades e de idéias religiosas, associação, adaptação e equivalência de divindades, ilusão de catequese e outras. (FERRETI, 1995, p. 41) 
procura espiritual dos errantes da Nova Era vem contribuindo, assim, para a construção de uma religiosidade aberta à apropriação de técnicas espirituais e modelos religiosos os mais diversos, tendendo, portanto, a ser sincrética e vaga." (Amaral, 1999, p. 71). A autora nos traz ainda que, o sincretismo existente no universo da Nova Era traz algumas características próprias, quais sejam:

$1^{\text {a }}$. Não se trata de tradições religiosas em confronto, em luta ou resistência uma em relação às outras;

$2^{a}$. A experimentação é a idéia matriz da cultura Nova Era face aos modelos morais e religiosos contemporâneos, apontando para um elemento crítico que penetra em seus espaços rituais;

3a. A mistura que aí se observa constitui-se a partir de um desejo de exceder limites de significação impostos pela cultura moderna, ordenadora do trânsito, levando, ao invés da afirmação da tradição dominante, a uma abertura de seus campos de sentido. (Amaral, 1999, p. 71-72)

A autora argumenta em torno de que não seriam os conteúdos das crenças a fonte de sentido das práticas, mas sim a forma como os "errantes" podem se relacionar com os diversos campos de crença. Bittencourt Filho (2003) compartilha desta posição ao situar que na Nova Era não é a profundidade das experiências, mas sim a pluralidade destas que terá um peso decisivo sobre as práticas dos agentes.

No entanto, devemos retomar aqui os argumentos postos por Magnani (1999; 2000), e por Guerriero (2006), que pontuam em torno de como a Nova Era abarca, por um lado, uma infinidade de práticas, movimentos, etc, incluindo aí sociedades iniciáticas, congregações religiosas estáveis (próximas do que Durkheim chama de Igrejas) etc, e por outro, uma infinidade de possibilidades de se relacionar com o sagrado, de modo que não podemos generalizar as formas pelas quais os sujeitos se relacionam com o universo religioso na Nova Era, cabendo também às possibilidades postas por Amaral, mas não só estas. Magnani (1999; 2000) chega a criar uma tipologia destes praticantes, dividindo-os da seguinte forma: o erudito, o ocasional e o participativo, que apontam para os tipos mais recorrentes, porém não são 
os únicos, e se aproximam muito mais de "tipos ideais", que de sujeitos reais, já que as trajetórias dos sujeitos são demasiadamente irregulares e híbridas.

Num extremo estaria o erudito, marcado, não por uma postura mais "científica", ainda que este discurso seja utilizado por vezes na Nova Era, como é o caso clássico do Fritjof Capra com O Tao da Física, mas sim por uma postura mais sistemática de se relacionar com este universo. Para o autor "Mesmo no contexto da Nova Era, com todo o seu sincretismo, há lugar para soluções e experimentos sofisticados por parte de pessoas que buscam saídas não-convencionais sem, contudo, cair na banalização." (Magnani, 2000, p. 48)

No outro extremo encontraríamos o ocasional, marcado por escolhas aleatórias movidas muitas vezes por modismo, curiosidade, ou por uma necessidade pontual. E entre estes dois extremos estaria o participativo, que:

[...] ao contrário do ocasional, possui conhecimentos e informações que the permitem estabelecer relações entre elementos escolhidos (por exemplo, as ideias de carma, aura, circulação do ch'i, meridianos, chakras, entre outros) e as fontes correspondentes, ou ao menos reconhecer as diferenças entre eles. Mas ao contrário do erudito, o tipo participativo não necessariamente organiza sua visão de mundo e comportamento por algum sistema em especial; transita mais livremente entre eles - ainda que respeitando algum nível de coerência. (Magnani, 2000, p. 49)

Temos, portanto, um cenário bem mais plural, que abarca enésimas possibilidades de vivência do sagrado. Por consequência, a forma como o sincretismo se apresenta na Nova Era brasileira, é também plural. A sensação em princípio pode parecer ser de um carnaval, no qual a ordem tida como padrão no campo religioso, é subvertida. Há um espaço sempre em aberto a ser preenchido, os sujeitos se permitem criar formulações ad hoc, para situaçóes postas, ainda que no caso das sociedades iniciáticas, o peso da instituição é considerável, de modo que há um menor espaço de flexibilização, porém maior que aquele encontrado nas instituições tradicionais.

Outro aspecto que deve ser destacado é como a Nova Era, no Brasil, toma contornos singulares, ao incorporar elementos historicamente estigmatizados. 
Trazemos aqui tal colocação como algo que vai à contramão de alguns autores já consagrados na discussão da temática. Amaral (2003) nega que possa haver qualquer indigenização na Nova Era brasileira, pois segundo a autora "[...] tais incorporações 'nacionais' não fogem à lógica da transitividade da religião no mundo contemporâneo, especialmente desta cultura religiosa errante da qual estamos tratando." (Amaral, 2003, p. 47). Já Magnani (2000; 2006), destaca como há poucas referências a elementos da religiosidade brasileira no universo da Nova Era aqui experenciado, segundo o autor:

[...] cabe assinalar que as referências são geralmente aos povos andinos, a índios do território norte-americano e ao xamanismo 'clássico' do norte da Ásia. Apesar da rica tradição dos cultos afro-brasileiros, elementos rituais e cosmológicos da religião dos orixás, com poucas exceções, não são incorporados pela Nova Era. No que se refere às culturas indígenas, a aproximação é maior, principalmente de alguns povos e também com a doutrina do Santo Daime, em suas diferentes derivações. (Magnani, 2000, p. 39)

Argumentamos aqui, primeiramente, que há sim um aspecto singular da Nova Era no Brasil, ao incorporar elementos que inicialmente não estavam presentes em seu discurso originário, invertendo simbolicamente uma lógica social e cultural, no que diz respeito ao trazer elementos de religiōes historicamente estigmatizadas, como é o caso das religiōes afro-brasileiras. Tal movimento passa a ganhar visibilidade a partir dos anos 80 e 90, em especial através de religiosidades como o Vale do Amanhecer e o Santo Daime.

Nossa segunda argumentação, em parte já apresentada, é de que os elementos presentes nas religiōes afro-brasileiras, bem como no catolicismo popular, no kardecismo, e mesmo nas práticas das culturas indígenas, são incorporadas, ainda que, por muitas vezes, ressignificadas (Medeiros, 1998, Oliveira, 2009).

Devemos chamar a atenção para o fato de que, o bojo da Nova Era está atrelado ao movimento de contracultura, a um projeto alternativo de sociedade, de práticas culturais, através de um entrecruzamento de uma miríade de discursos. Ao trazermos este elemento, devemos destacar também que as próprias religiões afro-brasileiras ganham visibilidade com o 
movimento de contracultura no Brasil, que levou a uma busca por "nossas raízes", segundo Prandi (2005):

Mais tarde, no final da década de 1960 e começo da seguinte, teve início junto às classes médias do Sudeste a recuperação das raízes de nossa civilização, reflexo de um movimento cultural muito mais amplo, denominado contracultura. Forte revitalização das origens culturais brasileiras, sobretudo as africanas preservadas nos velhos templos dirigidos pelas mães e pais-de-santo, alimentou a renovação das artes e redefiniu sentidos de antigos valores estéticos, filosóficos e religiosos. Abriu-se para o Brasil como um todo, uma espécie de baú cultural pleno de ingredientes originais para novas criações e inventos, segredos guardados nos velhos candomblés da Bahia. (Prandi, 2005, p. 130).

Este "reencontro com as raízes brasileiras" através dos cultos afrobrasileiros não sublimou a estigmatização histórica em torno dos mesmos. Entretanto, é inegável que o cenário foi alterado, mudança esta que já estava em curso, cujo caso mais emblemático é o da umbanda, através de seu embranquecimento (Ortiz, 1999), ao incorporar elementos do espiritismo kardecista.

A Nova Era no Brasil ao sincretizar realiza tal processo dentro de uma brasilidade, com o famoso jeitinho, fala-se em preto-velhos, caboclos, Iemanjá, etc, mas quando indagamos aos nossos informantes se estes são os mesmos daqueles encontrados na umbanda e no candomblé, eles enfaticamente destacam que não são, só se aparentam na imagem, mas são outros, seres de luz, evoluidos espiritualmente, que estão aqui para fazer caridade. Neste sentido, encontramos a incorporação do espiritismo kardecista, como um elemento fundamental para cimentar as práticas sincréticas, já que ele remete a uma religião de mediação, ao mesmo tempo próxima das práticas dos cultos afro-brasileiros, por ser uma religião de possessão, mas ao mesmo tempo distante simbolicamente ao ser uma religião de brancos $e$ letrados. Tomemos como exemplo a partir daqui o caso específico que ocorre 
no Vale do Amanhecer ${ }^{6}$, que entendemos ser um caso emblemático desta singularidade do sincretismo da Nova Era no Brasil.

\section{ENTRE MANTRAS, CABOCLOS E CORES: O VALE DO AMANHECER E SUA SINGULARIDADE}

Brasília ergue-se no coração do Brasil em meio não só a concreto e projetos políticos, mas também embebida numa série sonhos e projetos oníricos, talvez mesmo expressos em sua arquitetura, em seu plano piloto, que para alguns, forma um avião, mas para outros, forma uma cruz. Dentre estes sonhos talvez o mais famoso seja aquele que antecede sua construção, o de Dom Bosco, que em 1883 sonhou que entre os paralelos $15^{\circ}$ e $20^{\circ}$ surgiria a terra prometida, vertendo leite e mel, justamente na localização atual de Brasília. Este sonho soa como profético para muitos movimentos espirituais e espiritualistas que surgiram em Brasília, legitimando simbolicamente a existência de uma pluralidade de práticas religiosas/espirituais/ espiritualistas/holísticas.

Quando no final dos anos 50 Brasília começa a ser erguida Neiva Chaves Zelaya já estava pela região, como candanga viúva e com quatro filhos trabalhou com caminhoneira, e mudou-se para o Núcleo Bandeirante onde se alojaram aqueles que trabalhariam na construção da Nova Capital Federal. Segundo os adeptos do movimento, aos 33 anos Tia Neiva, como ficou mais conhecida, passou a manifestar a sua mediunidade, apresentando visões de uma entidade que se denominava Pai Seta $\mathrm{Branca}^{8}$, que vem a ser o mentor espiritual do movimento.

${ }^{6}$ Os dados tomados neste artigo são frutos de pesquisas de Campo realizada nas cidades de Campina Grande - PB, Olinda, São Lourenço e Recife - PE, Maceió - AL, e Brasília - DF, em nível de mestrado e de doutorado.

${ }^{7}$ Nome dado aos migrantes que trabalharam durante a construção de Brasília.

${ }^{8}$ Para os adeptos, a figura do Pai Seta Branca é entidade que hierarquicamente vem logo abaixo de Jesus, ou melhor, é o seu "Sétimo Raio" e Tia Neiva é o "Sétimo Raio" do Pai Seta Branca. Para Mello (1999), sua figura chega mesmo a ser confundida com Jesus Cristo por vezes. 
Em busca de respostas para o fenômeno que vivenciava, através das visões que passou a ter, Tia Neiva peregrina no catolicismo, sua primeira religião, bem como na medicina, e por fim no kardecismo, onde conhece Mãe Neném com quem chega a fundar a União Espiritualista Pai Seta Branca - UESB 9 .

No período em que esteve ligada à UESB (1959-1964), Neiva afirma ter sido treinada por um monge "encarnado" de nome Humahã, que residiria no mosteiro de Lhasa no Tibet. Segundo os adeptos, durante 5 anos Neiva teria se transportado espiritualmente todos os dias para receber o referido treinamento. Ao final do mesmo, ela teria recebido o nome de "Koatay 108", que faria referência a uma suposta coroa luminosa composta de 108 diamantes que teria sido posta dali em diante sobre sua cabeça, bem como ao conhecimento de 108 mantras, ambos proporcionados pelos planos espirituais.

Houve posteriormente divergencias entre Tia Neiva e Mãe Nenen que culminaram com a separação das duas. Segundo Cavalcante (2000) este fato é explicado entre os adeptos como cumprimento de uma "dívida cármica", já que elas teriam sido ligadas em vidas passadas e o tempo que passaram juntas teria servido para sanar esta "dívida".

Em 1964, Tia Neiva muda-se para os arredores de Taguatinga junto a um pequeno grupo de médiuns. Nesta cidade é registra sua obra missionária com o nome de "Ordens Sociais da Ordem Espiritualista Cristã". Na verdade foi apenas uma mudanaça de nome, pois já havia um registro sob os moldes de comunidade religiosa com obras sociais, que permaneceu sob o nome de "União Espiritualista Seta Branca". Segundo os adeptos, no plano espiritual a comunidade teria o nome de "Corrente Indiana do Espaço". Tempos

\footnotetext{
${ }^{9}$ É válido destacar que, quando é narrada a biografia de Tia Neiva, seja pelos adeptos em seus relatos, seja através dos livros publicados pelo movimento, sempre é destacado o quanto que Tia Neiva teve resistência em aceitar sua mediunidade, justamente por provir de uma família católica, o que só foi superando quando ao procurar um psiquiatra, ela relata suas visóes, dentre elas, uma que estaria sendo vista naquele momento, e ao narrar sua visão ao psiquiatra este reconhece a mesma como seu próprio pai, que há pouco falecera. Quando Tia Neiva não encontra respostas para as suas visões nem mesmo na medicina oficial decide, portanto, aceitar e se dedicar a sua mediunidade.
} 
depois agregou-se a este grupo uma pessoa que será decisiva no processo de constituição do Vale, Mário Sassi, terceiro e último companheiro de Tia Neiva e que veio a se tornar o principal sistematizador da doutrina do Vale do Amanhecer. Ele teria chegado ao Vale em decorrência de problemas espirituais que o teriam levado à depressão e ao alcoolismo (Gonçalves, 1999).

No que se refere ao templo propriamente dito, houve problemas judiciais que acarretaram a perda do terreno no qual o grupo de Tia Neiva estava alojado, fazendo-se necessária mais uma mudança de local. O grupo se muda para os arredores de Planaltina, Cidade Satélite de Brasília, onde finalmente se concretiza a instalação da comunidade. É neste local que a doutrina ganha entre os adeptos o nome de Vale do Amanhecer, fazendo uma referencia à auba avistada daquele local. Houve ainda um processo de desaproriação deste terreno devido à construção de uma usina hidrelétrica que abasteceria Brasília. Entretanto, devido à adesão de novos membros e consequente aumento populacional houve a concessão do terreno a Neiva, que passou a determinar por meio de venda de lotes quem deveria ou não viver no Vale.

Tia Neiva morre em 1985, aparentemente, em decorrência de turbeculose. Para os adeptos, tal doença tinha uma explicação espiritual, decorreria de uma divida cármica teria ocorrido após o seu treinamento com o monge tibetano. Antes de sua morte, Neiva havia deixado preparada a sua sucessão, cabendo a quatro trinos ${ }^{10}$ o comando do Vale a partir deste momento estes trinos são Mário Sassi (Trino Tumuchy), seu filho, Gilberto Chaves Zelaya (Trino Ajarã), os adeptos Nestor Sabatovicz Trino Arakém) e Michel Hanna (Trino Sumanã). Às duas filhas de Tia Neiva couberam alguns poucos encargos secundários na doutrina.

${ }^{10} \mathrm{~A}$ atual estrutura hierárquica existente no VDA foi definida por Tia Neiva, ainda em vida (Reis, 2008). No nível máximo da hierarquia do movimento encontra-se o Conselho dos Trinos, que são responsáveis pela manutenção doutrinária do VDA, e pelas atividades burocráticas da doutrina, devendo se destacar o fato que, tal conselho foi incapaz de manter a liderança carismática exercida por Tia Neiva (OLIVEIRA, 2002). Este Consetho de Trinos foi formado, inicialmente, pelos filhos homens de Tia Neiva, Mário Sassi (falecido em 1995) e Nester Sabatovicz (falecido em 2004), de modo que, atualmente apenas os filhos de Tia Neiva compóem este conselho. 
Chama a atenção o fato de que no ano da morte de Neiva havia apenas quatro templos fora de Brasília, hoje já existem mais de 600, sete dos quais em outros países, segundo Cavalcante (2005). Em sua pesquisa, a autora encontrou adeptos em Brasília que se sentiam incomodados com tal situação, citando que há templos, como o do Recife, que haviam introduzido mudanças de termos rituais e doutrinários, o que seria contrario à perspectiva vigente no Vale, que segundo Medeiros (1998) garante autonomia administrativa aos templos porém não doutrinária.

Batista (2003) pontua acerca do processo mítico de criação do universo particular do VDA: "Os adeptos do Vale do Amanhecer recriam de um modo próprio a sociedade, sua história, desde a Antiguidade até os discos voadores. Graças ao imaginário, os adeptos inventam um eixo temporal que lhes permite atravessar todas as épocas da humanidade" (Batista, 2003, 11).

A constittuição do universo religioso do Vale imbrica elementos presentes na religiosidade popular com elementos trazidos das mais diversas matrizes culturais. Em termos iconográficos elementos trazidos de seriados de TV, filmes de faroeste também são trazidos como referência cultural. Como nos aponta Cavalcante (2005):

O Vale do Amanhecer fala de povos indígenas andinos, meso-americanos, brasileiros e norte-americanos, todos eles expostos a uma forte aura mítica e aparentemente lá chegados por intermédio de sistemas como folhetos de agencias de turismo e lembranças adquiridas nas viagens; assim como da religião umbandista; da religiosidade Nova Era e também dos filmes e séries de faroeste, veiculados no cinema e na televisão. O interessante é que, no Vale, esses mesmos índios também dizem respeito a informações referentes a naves espaciais, a seres de outros planetas, a faraós e pirâmides egípcias, entre outros. Tudo isso ocasionado por o "Vale indígena" ser um texto, no qual a tessitura a ele imanente, sendo híbrida, dá-se a realizar de modo dialógico e complexo. (Cavalcante, 2005, p. 168)

Tal caracteristica, de fato, é encontrada no universo da Nova Era de modo geral, naquele chamado Sincretismo em Movimento, apontado por Amaral (1999). No entanto, trazemos como característica singular do Vale 
a possibilidade de arranjar elementos presentes em sistemas culturais historicamente estigmatizados, ressignificando os mesmos e articulando com elementos distintos.

Em nossa argumentação situamos que a Nova Era, tal como ela se apresenta no Brasil, traz elementos novos, não presentes em seus discursos e práticas originários, bem como perfazendo uma nova ordem simbólica, trazendo enquanto elementos de legitimação religiosa signos historicamente ilegitimos, ou ao menos estigmatizados.

No Vale do Amanhecer caboclos incorporam em médiuns ${ }^{11}$, ao mesmo tempo que eles quando incorporados fazem referências a Iara, Iemanjá, Princesas Encantadas, Cavaleiros do Oriente, Dr. Fritz, Bezerra de Menezes etc. Imagens de índios, pretos velhos habitam pirâmides egípcias, juntamente com outras que lembram hindus, e outros que se apresentam como seres intergaláticos.

O sincretismo de seu universo se dá também no plano linguístico as músicas entoadas, no decorrer dos trabalhos mediúnicos, são chamadas pelos médiuns de mantras, e fazem referência aos pretos velhos, a Jesus Cristo, ao Pai Seta Branca, às diversas entidades cultuadas neste movimento.

Esta singularidade do movimento perpassa a experiência mediúnica. A vivência biográfica que é alterada pela imersão no movimento, também modifica a forma como a nova experiência é interpretada pelos sujeitos. A experiência toca também a dimensão da corporeidade, em especial para aqueles que são médiuns tidos como aparás, pois sua incorporação performática situa-o no espaço social, ao mesmo tempo em que transparence sua vivência religiosa anterior.

Normalmente no Vale a incorporação se dá através dos Caboclos e dos Pretos-Velhos, que possuem caracteristicas singulares quando incorporados

${ }^{11}$ No Vale do Amanhecer existem dois tipos de médiuns: Doutrinador, aquele responsável pela recepção dos médiuns e frequentadores (chamados de pacientes), como também pelo diálogo com as entidades, e Apará, responsável pela incorporação tanto dos espíritos de luz, que ajudarão no trabalho mediúnico, como dos cobradores que são entidades espirituais que, normalmente, foram prejudicadas em vidas passadas pelo paciente, ou seja, por aquele que sofre com a atuação dos cobradores. 
pelos médiuns. Ortiz (1999) ao analisar a incoporação na Umbanda traz as seguintes caracteristicas, primeiramente sobre os caboclos:

Os caboclos são espíritos de nossos antepassados índios que passaram depois da morte a militar na religião umbandista. Eles representam a 'energia e a vitalidade'; podem-se encontrar estas caracteristicas de arrojo no mimetismo do transe. A chagada de um caboclo vem sempre acompanhada de um grito forte que denota a energia e a força desta entidade espiritual: eles são espíritos indóceis rebeldes (traços do selvagem?) que batem fortemente os punhos cerrados contra o peito à guisa de saudação. (Ortiz, 1999, p. 71)

Acerca dos pretos velhos ele pontua:

Os pretos velhos são espíritos dos antigos escravos negros que pela sua humildade tornaram-se participantes da 'Lei da Umbanda'. Quando eles descem, o corpo do neófito se curva, retorcendo-se como o de um velho esmagado pelo peso dos anos. (...) Falam com uma voz rouca, mas suave, cheia de afeição, o que transmite uma sensação de segurança e familiaridade àqueles que vêm consultá-los. (Ortiz, 1999, p. 73)

Cancone (2004) busca sintetizar as distinções presentes nestas duas entidades, colocando-as em oposição, de um lado o Preto-Velho, que representa a velhice, a fragilidade, a bondade, a calma, por outro o Caboclo, que representa a juventude, a força, a justiça, a agitação/movimento. Também no plano gestual, e das expressóes fisionômicas a autora situa-os da seguinte forma: Pretos-Velhos; postura curvada, movimentos lentos, dificuldade de movimento, Caboclos; postura ereta, movimentos rápidos, saltos, andar vigoroso.

O estranhamento vivenciado no Vale é também acompanhado por uma sensação de familiaridade, seja pelas entidades em si, seja pela experiência de incorporação, esta se apresenta como um amplo código acessado por aqueles que possuem e professam os mais diversos credos, ainda que tal código seja, neste contexto, manipulado de modo que se possa acessar referências mais amplas, e ao mesmo tempo simbolicamente mais eficazes. 
No entanto, devemos distar aqui a performance vivenciada no Vale do Amanhecer daquela existente na umbanda, uma vez que, as posições entre caboclo e preto-velho aqui são mais próximas, já que o médium pode ser inicialmente de incorporação e tornar-se um doutrinador (ou o inverso), bem como ele pode incialmente incorporar caboclos e posteriormente incorporar pretos-velhos. Os próprios adeptos, quando inqueridos qual a diferença entre as entidades presentes no Vale e aquelas presentes na Umbanda, fazem questão de destacar que no Vale do Amanhecer os preto velhos e caboclos não consomem álcool, charutos, nem interferem no livre arbítrio dos sujeitos.

Outra questão relevante diz respeito às relações de gênero, uma vez que no Vale as mulheres têm a liberdade de incorporar entidades femininas, ou masculinas, ao passo que os homens só podem incorporar entidades exclusivamente masculinas, o que levaria a outras questōes nas relaçôes de gênero entre as ninfas e os jaguares ${ }^{12}$, que não abordaremos neste trabalho.

Devemos destacar o lugar que a incorporação ocupa na dinâmica social do Vale, pois é através deste fenômeno que o médium bate o peito, gargalha, sussurra, treme as mãos, dá conselhos. Sua performance permite criar uma dimensão intersubjetiva entre o médium e aquele não iniciado, que procura os serviços espirituais do Vale. Ao mesmo tempo diz algo sobre o mesmo, situa-o no espaço social, como já afirmamos, afinal, a qualidade da performance diz muito sobre o médium: tempo na doutrina, percurso religioso, grau de eficácia de seus trabalhos.

Tal vivência religiosa traz novas possibilidades e novos arranjos, permitem a sensação de déjà vu acompanhada da impressão de nunca ter visto ou vivenciado algo do tipo. Sem dúvidas o Vale do Amanhecer aponta para um caso limite da singularidade da Nova Era no Brasil, de quão plástico pode ser tal movimento, em especial no que tange à incorporação de elementos pertencentes à religiosidade popular.

\footnotetext{
${ }^{12} \mathrm{Na}$ linguagem utilizada pelos adeptos do Vale do Amanhecer são chamados de jaguar os homens, de modo geral, que podem ser príncipes ou magos, de acordo com a falange espiritual, e de ninfa as mulheres, que se filiam também a uma falange espiritual, dentre as 19 possíveis.
} 


\section{CONSIDERAÇÕES FINAIS}

No decorrer deste trabalho realizamos apontamentos em torno da questão da Nova Era no Brasil, considerando seu caráter singular ao se articular com elementos diversos daqueles presentes em sua configuração original, não que com isso o fenômeno tome aqui contornos completamente distintos daqueles existentes em outras temporalidades e em outros espaços, não à toa nos utilizamos ainda da categoria Nova Era para classificar tais práticas, no entanto, damos relevo às peculiaridades assumidas neste momento histórico no Brasil dentro deste universo simbólico, destacando que não se trata aqui de uma simples transposição automática de um movimento religioso e intelectual.

Suas transformações, longe de serem frutos apenas de mudanças no campo religioso de forma autônoma, representam uma mudança no plano macrossocial que abarca o âmbito político, étnico, econômico etc, de modo que apenas as ferramentas analíticas propostas pelos autores que se consolidaram neste campo de estudos não nos são suficientes para compreender o fenômeno, ainda que sejam indispensáveis.

Entendemos que as práticas neste universo buscam viabilizar a abertura para outras possibilidades de arranjos e rearranjos, que se articulam de forma a construir uma realidade simbolicamente capaz de gerar sentido para os sujeitos envolvidos, que tanto podem estar comprometidos apenas consigo centrando-se na multiplicidade de experiência apenas, como também podem voltar-se para um compromisso com a coletividade focando na profundidade das experiências. Ao contrário da literatura recorrente acerca do universo da Nova Era, encontramos no Vale uma prática religiosa essencialmente comunitária, o caráter iniciático mostra-se como condição sine qua non para o desenvolvimento mediúnico, e mesmo para o caminho do autoconhecimento.

Podemos afirmar, portanto, que ainda que neste campo a "religiosidade do self ganhe destaque, há espaços voltados para os movimentos iniciáticos, com seus complexos graus hierárquicos e com seu profundo movimento de ressocialização dos adeptos. 
$\mathrm{Na}$ Nova Era brasileira não é apenas a sensação de surpresa, e de novo, que assola aqueles que se voltam para a sua experiência, também há um profundo sentimento de déjà $v u$, há um reconhecimento de símbolos que fazem parte tanto de uma narrativa local como global, ainda que estes devam muitas vezes ser reapreendidos, devido ao intenso processo de ressignificação.

Afirmamos por fim o caráter plural destas práticas, pois não apenas emergem novas práticas e discursos como outros imergem nestes, pais-desanto que realizam sessões de Reike, kardecistas que se utilizam de florais, de cristais, rezadeiras que leem o horóscopo, revistas que sobrepõem os signos aos orixás, foram alguns dos exemplos que encontramos ao explorar o campo da Nova Era no Brasil. A discussão ainda é incipiente, porém necessária, uma vez que nos encontramos ante um cenário de pluralidade religiosa em que há um entrecruzamento de discursos e práticas, uma explosão de novas realidades religiosas que demandam novos aportes analíticos por parte das ciências sociais para a sua compreensão e investigação.

\section{REFERÊNCIAS}

ALBUQUERQUE, Leila Marrach Basto de. Estrutura e Dinâmica dos Novos Movimentos Religiosos. In: SOUZA, Beatriz Muniz de; SÁ MARTINO, Luís Mauro (Orgs.). Sociologia da religiāo e mudança social. São Paulo: Paulus, 2004.

AMARAL, Leila. Carnaval da alma: Comunidade, essência e sincretismo na Nova Era. Petrópolis: Vozes, 2000.

. Sincretismo em Movimento - O Estilo Nova Era de lidar com o sagrado. In: CAROZZI, María Julia (Org.). A Nova Era no Mercosul. Petrópolis: Vozes, 1999.

. Um Espírito sem lar: sobre uma dimensão nova era da religiosidade contemporânea. In: VELHO, Otávio Guilherme (Org.). Circuitos Infinitos: Comparações e religiões no Brasil, Argentina, Portugal, França e GrãBretanha. São Paulo: Attar, 2003. 
ANDRADE, Maristela de Oliveira. 500 anos de catolicismos \& sincretismos no Brasil. João Pessoa: Editora Universitária/UFPB, 2002.

BATISTA, Marilda Manoel. Rituais religiosos e mise en scène filmica: o exemplo do Vale do Amanhecer (D.F., Brasil). Revista Chilena de Antropologia visual, Namur, Chile, v. 3, 2003. Disponível em: <www.antropologiavisual. cl/ Marilda_Batista.htm>. Acesso em 30 de março de 2011.

BASTIDE, Roger. As religioes africanas no Brasil: Contribuição a uma sociologia das interpretações de civilizações, v. 2, São Paulo: Pioneira, 1985. BITTENCOURT FILHO, José. Matriz Religiosa Brasileira: Religiosidade e Mudança Social. Petrópolis: Vozes; Rio de Janeiro: KOINONIA, 2003. . O Candomblé da Bahia. São Paulo: Companhia das Letras, 2001. BRANDÃO, Carlos Rodrigues. Fronteira da fé: alguns sistemas de sentido, crenças e religiōes no Brasil de hoje. Estud. av., dez. 2004, v. 18, n. 52. p. 261-288.

CANCLINI, Néstor García. Culturas Hibridas - estratégias para entrar e sair da modernidade. São Paulo: EDUSP, 1997.

CANDONE, Maria Helena Villas Boas. Caboclos e Pretos-Velhos da Umbanda. In: PRANDI, Reginaldo. Encantaria Brasileira: o Livro dos Mestres, Caboclos e Encantados. Rio de Janeiro: Pallas, 2004.

CARVALHO, José Jorge de. O encontro de novas e velhas religiōes: esboço de uma teoria dos estilos de espiritualidade. In: MOREIRA, Alberto; ZICMAN, Renée (Orgs.). Misticismo e novas religiōes. Petrópolis: Ed. Vozes, 1994, p. 67-98.

. Um espaço público encantado. Pluralidade religiosa e modernidade no Brasil. Série Antropológica, Brasília, ano de 1999, n. 249. Disponível em $<$ http://www.unb.br/ics/dan/Serie249empdf.pdf.>. Acesso em 30 de mar. 2011. 
CAROZZI, María Julia. Nova Era: a Autonomia como Religião. In: CAROZZI, María Julia (Org.). A Nova Era no Mercosul. Petrópolis: Vozes, 1999.

CAVALCANTE, Carmen Luisa Chaves. Dialogias no Vale do Amanhecer: Os Signos de um Imaginário Religioso Antropofágico. 2005. 242f. Tese (Doutorado em Comunicação de Semiótica), Pontifícia Universidade Católica de São Paulo, São Paulo. . Xamanismo no Vale do Amanhecer: O caso Tia Neiva. São Paulo: Annablume, 2000.

DAMATTA, Roberto. Casa \& Rua. Rio de Janeiro: Companhia das Letras, 1997.

ELIADE, Mircea. O Mito do Eterno Retorno. Lisboa: Ediçōes 70, 2000. FANON, Franz. Peles Negras, Máscaras Brancas. Salvador: Edufba, 2008. FERRETTI, Sérgio F. Repensando o Sincretismo. São Paulo/São Luís: EDUSP/FAPEMA, 1995.

FREYRE, Gilberto. Casa Grande \& Senzala. São Paulo: Global, 2005. GIDDENS, Anthony. As Consequências da Modernidade. São Paulo: UNESP, 1991.

GONÇALVES, Djalma Barbosa. Vale do Amanhecer: Análise Antropológica de um Movimento Religioso Sincrético Contemporâneo. Brasília. Monografia (Graduação em Antropologia), Universidade de Brasília, 1999.

GUERRIERO, Silas. Novos movimentos religiosos: o quadro brasileiro. São Paulo: Paulinas, 2006.

HALL, Stuart. A Diáspora. Belo Horizonte: Editora UFMG, 2009.

HERVIEU-LÉGER, Danièle. O Peregrino e o Convertido: a Religião em Movimento. Petrópolis: Vozes, 2008.

HOLANDA, Sergio Buarque de. Raizes do Brasil. São Paulo: Companhia das Letras, 2006. 
MAGNANI, José Guilherme Cantor. Mystca Urbe: um Estudo Antropológico Sobre o Circuito Neo-Esotérico na Metrópole. São Paulo: Studio Nobel, 1999 .

. O Brasil da Nova Era. Rio de Janeiro: Jorge Zahar Ed., 2000.

. O circuito neo-esotérico. In: TEXEIRA, Faustino; MENEZES, Renata (Orgs.). As Religiōes no Brasil: Continuidades e rupturas. Petrópolis: Vozes, 2006.

MAGGIE, Yvonne. O Medo do Feitiço: Relacoes entre Magia e Poder no Brasil. Rio de Janeiro: Arquivo Nacional, 1992

MEDEIROS, Bartolomeu Tito Figueirôa de. Um caso de sincretismo afrocristão-kardecista-umbandista-new age: As casas filiais do Vale do Amanhecer, no Nordeste brasileiro. In: XXI Reunião brasileira de antropologia. Vitória: Reunião brasileira de Antropologia, 1998.

MELLO, Glaúcia Buratto Rodrigues de. Milenarismos Brasileiros: Novas Gnoses, Ecletismo Religioso e uma Nova Era de Espiritualidade Universal. In: MUSUMECI, Leonarda (Org.). Antes do Fim do Mundo: Milenarismos e Messianismos no Brasil e Argentina. Rio de Janeiro: Editora UFRJ, 2004. - Millenarismes bresiliens: Contribution à l'étude de l'imaginaire contemporain. These de docteur em sociologie. Université Pierre Mendes France, U.F.R. Sciences de l'homme et la societé, Departament de Sociologie. Grenoble, 1999.

MARTINS, Paulo Henrique. As Terapias Alternativas e a Libertação dos Corpos. In: María Julia Carozzi. (Org.). A Nova Era no Mercosul. Petrópolis: Editora Vozes, 1999.

MUNANGA, Kabengele. Art africain et syncretisme religieux au Brésil. Revista do Museus de Arqueologia e Etnologia. São Paulo, USP, n. 27, 1989.

OLIVEIRA, Amurabi Pereira de. Dinâmicas culturais e relações de reciprocidade no Vale do Amanhecer: um estudo de caso sobre o templo de 
Campina Grande. Campina Grande. Dissertação (Mestrado em Ciências Sociais). Universidade Federal de Campina Grande, 2008.

. Nova Era à Brasileira: a New Age Popular do Vale do Amanhecer. Interaçóes Cultura e Comunidade. jan./jun. 2009, v. 4, n. 5.

. Religião e Sociedade Pós-Tradicional: o Caso da New Age Popular do Vale do Amanhecer. Revista Brasileira de História das Religiões, v. Ano II, 2010.

OLIVEIRA, Dorotéo Émerson Storck de. As Representações do Sagrado na Construção da Realidade no Vale do Amanhecer. Goiânia. Dissertação (Mestrado em Ciências da Religião), Pontifícia Universidade de Goiás, 2002.

ORTIZ, Renato. A Morte Branca do Feiticeiro Negro: Umbanda e Sociedade Brasileira. São Paulo: Brasiliense, 1999. . Mundialização e Cultura. São Paulo: Brasiliense, 2006.

PRANDI, José Reginaldo. Segredos Guardados: Orixás na Alma Brasileira. São Paulo: Companhia das Letras, 2005.

RODRIGUES, Raimundo Nina. O Animismo Fetichista dos Negros Baianos. Rio de Janeiro: Fundação Biblioteca Nacional/Editora UFRJ, 2006.

REIS, Marcelo Rodrigues dos. Tia Neiva: a Trajetória de uma Líder Religiosa e sua Obra, O Vale do Amanhecer (1925-2008). Brasília, Tese (Doutorado em História), Universidade de Brasília, 2008.

SAID, Edward W., Orientalismo: o Oriente como Invenção do Ocidente. São Paulo: Companhia das Letras, 2007.

SANCHIS, Pierre. Inculturação? Da Cultura à Identidade, Um Itinerário Político no Campo Religioso: o Caso dos Agentes de Pastoral Negros. Rel. Soc., v. 22, n. 2, p. 55-72, 1999.

. Pra não dizer que não falei de sincretismo. Comunicaçôes do ISER, v. 13, n. 45 , p. 4-11, 1994. 
. Religiōes, religião... Alguns problemas do sincretismo no campo religioso brasileiro. In: SANCHIS, P. (Org.) Fiéis e cidadãos: Percursos do sincretismo no Brasil. Rio de Janeiro: EdUERJ, 2001.

SILVA, Magnólia Gibson Cabral. Esoterismo e movimento esotérico no Brasil. Recife. Tese (Doutorado em Sociologia), Universidade Federal de Pernambuco, 2000.

SILVA, Vagner Gonçalves da. Neopentecostalismo e religiōes afro-brasileiras: Significados do ataque aos símbolos da herança religiosa africana no Brasil contemporâneo. Mana. Rio de Janeiro, v. 13, n. 1, p. 207-236, 2007

SIQUEIRA, Deis; LIMA, Ricardo Barbosa de (Orgs.). Sociologia das Adesões: Novas Religiosidades e a Busca Místico-Esotérica na Capital do Brasil. Rio de Janeiro: Garamond: Vieira, 2003.

SOUZA, Laura de Mello e. O diabo e a Terra de Santa Cruz: feitiçaria e religiosidade popular no Brasil colonial. São Paulo, Companhia das Letras, 1986.

VELHO, Gilberto. Projeto e Metamorfose: Antropologia das Sociedades Complexas. Rio de Janeiro: Jorge Zahar Ed., 2003. 